\title{
EL PERSONAJE DE MUERTE EN LA DANÇA GENERAL: ¿DOBLE POR FISIÓN O DOBLE POR FUSIÓN?
}

\section{THE CHARACTER OF DEATH IN THE DANÇA GENERAL: DOUBLE BY FISSION OR DOUBLE BY FUSION?}

\author{
Daniel Añua-Tejedor
}

Doctor por la UPV/EHU

\section{ABSTRACT}

The Danca general de la muerte presents the indissoluble reality of the human being fragmented into two differentiated characters coexisting in the same fictional world. In the Dança, Death dialogues and dances successively with his different dance partners. The death that awaits all living beings is presented to us as an independent entity that lives outside of us and that - at the end of our days - will come to exterminate us. Where does the need to create this literary character that shares diegèse with its home character come from? Do the motifs that led to its creation have any relation with the motifs that gave rise to the romantic doubles by fusion or fission? Is it possible to establish intertextual connections, for example, between Goliadkin II by Dostoyevsky and Death?

Key words: Dança; double; fusion; fission; Death 


\section{RESUMEN}

La Dança general de la muerte presenta la realidad indisoluble del ser humano fragmentada en dos personajes diferenciados coexistiendo en el mismo mundo ficcional. En la Dança, Muerte dialoga y baila sucesivamente con sus diferentes parejas de baile. La muerte que nos espera a todos los seres vivos se nos presenta como una entidad autónoma que habita fuera de nosotros y que -al final de nuestros días- vendrá a exterminarnos. ¿De dónde surge la necesidad de crear este personaje literario que comparte diégèse con el personaje de procedencia?, ¿los motivos que llevaron a su creación guardan alguna relación con los motivos que dieron lugar a los dobles románticos por fusión o fisión?, ¿es posible entablar conexiones intertextuales, por ejemplo, entre Goliadkin II de Dostoyevski y Muerte?

Palabras clave: Dança; doble; fusión; fisión; Muerte

Fecha de recepción: 19 de junio de 2020.

Fecha de aceptación: 1 de septiembre de 2020.

Cómo citar: Añua-Tejedor, Daniel (2020), «El personaje de muerte en la Dança general: ¿Doble por fisión o doble por fusión?», en Actio Nova: Revista de Teoría de la Literatura y Literatura Comparada, 4: 217-236.

DOI: https://doi.org/10.15366/actionova2020.4.010 


\section{EL DOBLE}

\subsection{MOTIVACIÓN AUTORAL PARA LA CREACIÓN DEL PERSONAJE}

La literatura europea, sobre todo a partir de la inflexión romántica, mueve a los autores a preguntarse quiénes son y si realmente son quienes creen ser (Martín López, 2006: 7). Esta indagación encuentra su reflejo en las obras que desvelan el mundo interior de los autores y en la configuración del personaje del doble que aparece en las mismas. Como recogen Jourde y Tortonese (2005: 86), tanto Otto Rank, Wilhelmine Kraus, Robert Rogers como Masao Miyoshi atribuyen a los autores románticos que utilizan el motivo literario del doble un malestar psicológico que descargarían sobre ce bouc émissaire, sobre este chivo expiatorio, que encarna dicho motivo. Así mismo, Juan Herrero Cecilia considera que:

[Otto Rank] otorga mucha importancia a la biografía de los escritores (sus manías, sus traumas neuróticos, sus obsesiones, alucinaciones y visiones) y explica las diversas manifestaciones de la figura mítica del doble en relación con las patologías mentales o las angustias existenciales experimentadas por los escritores (Herrero, 2011: 32).

Es necesario resaltar que, aunque no se puede esperar que «las taxonomías de los dobles literarios y de los trastornos clínicos se superpongan perfectamente», existen similitudes para intuir «un origen neurocognitivo común para ambos» (Dieguez, 2013: 81). En términos estrictamente psiquiátrico, el doble aparece como «a reaction to trends towards depression and self-destruction, it flourishes on states of dissociation, confusion, and depersonalization, and strives on paranoid beliefs» (Dieguez, 2013: 84). Según indica Jung, «Névroses et troubles psychiques proviennent de parties insuffisamment assimilées de la psyché» (Jourde et Tortonese, 2005: 69). La necesidad de integrar conscientemente lo que Jung define como sobra, es decir: «the dark aspects of the personality», requiere un esfuerzo moral considerable que encuentra una resistencia de la misma magnitud (Jung, 1970: 8). Los aspectos más difíciles de integrar acaban configurando proyecciones que difícilmente son reconocidas como tales y cuyo «recognition is a moral achievement beyond the ordinary» (Jung, 1970: 9). Dichas proyecciones cambian el entorno que nos rodea en «the replica of one’s own unknown face» (Jung, 1970: 10) lo que origina que solo podemos percibirlas con seguridad fuera de nosotros mismos (Zweig and Abrams, 2004: 17) independientemente de aceptarlas, de reconocerlas o no. 
En el caso del doble literario, estas proyecciones no aceptadas llevarían a la escisión del personaje en dos realidades autónomas compartiendo un mismo mundo ficcional. El personaje del doble materializa en la literatura este lado oscuro que el individuo o el personaje destierra (o pretende desterrar) al olvido en su vida cotidiana (Martín López, 2006: 31), exterioriza los aspectos negativos (la culpa o lo reprimido) a través de una escisión autónoma que atormenta con su presencia al protagonista (Gubern, 2002: 20) o encarna «une parte de la psyché qui se réifie dans une figure extérieure, visible, et agissant» que habría que integrar (Jourde et Tortonese, 2005: 116). El yo se convierte así en una figura del ideal, mientras que el doble encarna lo real. Según Jung, adoptamos una máscara para situarnos en el mundo, ocultando a los ojos de los demás esa parte de nuestro ser negada, rechazada o simplemente velada; $y$, por tanto, el doble desvela el engaño que supone dicha máscara o bien desnudando al individuo o bien obligándole a observarse descarnadamente (Martín López, 2006: 36).

Sea como fuere, el doble supone en muchos casos una amenaza; ya que, el sujeto teme desaparecer a manos de un doble que gozará de su vida en su lugar -como el sabio de los países fríos de Andersen a manos de su sombra-, ser ridiculizado públicamente -como Goliadkin I a manos de Goliadkin II en el capítulo octavo- o convertirse en un monigote detestable (Martín López, 2006: 39). El doble causa incomodidad y ansiedad debido a la duplicación «psychologique» que supone y a la duplicación «fantastique» percibida como anomalía en el orden de las cosas (Jourde et Tortonese, 2005: 3), ya que perturbar dicho orden natural causando angustia y desasosiego (Herrero, 2011: 22) — como relata el narrador de El Horla en su diario el 2 de junio-.

Pero la mayor amenaza la constituye el que el doble se convierte en muchos casos en un heraldo de la muerte del protagonista. Así aparece en la obra de Dostoievski, cuando un compañero de Goliadkin dice: «Una tía materna, antes de morir vio a su propio doble delante de ella» (Dostoievski, 2011: 91); o en palabras del propio doble cuando dice: «[...] me apeteció volver a verlo antes de que usted se muera, pues usted tiene que morir» en «La sombra» de Andersen (2005: 389).

\subsection{DEFINICIÓN Y DELIMITACIÓN DEL MOTIVO LITERARIO}

Desde el Romanticismo, el mito del doble es un tema recurrente en la literatura occidental, especialmente en la literatura llamada «fantástica» donde ha llegado a adoptar manifestaciones muy variadas que ponen de relieve significaciones y planteamientos bien 
diferentes (Herrero, 2011: 18). Sin embargo, para Otto Rank «Les premières manifestations de ce thème remontent, comme presque toujours en littérature, aux temps reculés du folklore, de la superstition ou de la naissance des religions» (2001: 11). Por tanto, debemos remontarnos al mito griego que narra el origen de Heracles $^{1}$ en la Antigüedad del que surge la comedia latina Amphitryon de Plauto (214 a. C.) que explota el potencial cómico de reunir en escena a dos parejas de personajes idénticos. La primera pareja está formada por el Anfitrión falso (Zeus) y el verdadero mientras que la segunda, por el Sosia falso (Mercurio) y el verdadero (un criado de Anfitrión típico en los papeles cómicos de las comedias). La visión amable y cómica del doble de Plauto dará paso a la lucha por poseer un nombre y una identidad desarrollada dieciocho siglos después por Jean de Rotrou (Les Sosies, 1636) y Molière (Amphitryon, 1668) en sus comedias (Jourde et Tortonese, 2005: 17-18). De este miedo a la desposesión, al «horreur d'une déréalisation ${ }^{2}$ du sujet» (Jourde et Tortonese, 2005: 19), el doble de la literatura del siglo XIX pasa a inscribirse «en una línea de interrogación acerca de la identidad y la unidad del individuo» (Martín López, 2006: 17), de extrañeza ante su mundo interior.

Este doble romántico aparece vinculado intertextualmente a manifestaciones recurrentes como: el espejo y el reflejo, la sombra, el retrato o el muñeco; y a unas secuencias narrativas concretas: el encuentro entre original y doble, la usurpación de personalidad en los ámbitos público y privado, la circularidad y la repetición, la duda sobre la propia identidad, o el intento de aniquilar al rival (Martín López, 2006: 15).

Tanto las manifestaciones como las secuencias enumeradas tienen su base en un encuentro en el que dos presencias de un mismo personaje coexisten compartiendo una diégèse ${ }^{3}$. Es entonces cuando el doble se hace presente y, siguiendo la definición de Jean Paul en Siebenkäs, «el individuo se contempla a sí mismo como un objeto ajeno gracias a una suerte de autoscopia» (Martín López, 2006: 18). Andrew J. Webber, en nota al pie, define este fenómeno como «the bilocation of the subject in the visual field» (1996: 3), mientras que

\footnotetext{
${ }^{1}$ Anfitrión, casado con Alcmena, es traicionado por Zeus que toma su apariencia para poder yacer con la recién casada. Alcmena dará a luz al hijo de Zeus, Heracles, y al hijo de Anfitrión, Ificles (Jourde et Tortonese, 2005: 17).

${ }^{2}$ Según la versión de internet del diccionario Larousse, el sentiment de déréalisation es un sentimiento de extrañeza pasajero ante la percepción del mundo exterior.

${ }^{3}$ Mientras que diégesis se opone a mímesis en la teoría platónica de los modos de representación, donde diégesis es el relato puro (sin diálogo), opuesto a la mímesis de la representación dramática y de todo aquello que, por medio del diálogo, se insinúa dentro del relato haciéndolo impuro, es decir, mixto; la diégèse, no es la historia, sino el universo en el que ocurre. Por consiguiente, no hay que sustituir historia por diégèse. $[. .$.$] diégèse [...] no$ es, en absoluto, la traducción francesa del griego diégesis (Genette, 1998: 15-16).
} 
Herdman considera que el doble es «a second self, or alter ego, which appears as a distinct and separate being apprehensible by the physical senses (or at least, by some of them), but exists in a dependent relation to the original» (1990: 14).

Por tanto, encontramos la presencia «del original (o primer yo) y su doble (segundo u otro yo)» simultáneamente en un mismo mundo ficcional (Martín López, 2006: 30) que Doležel definirá — como veremos_ en el tercero de sus temas.

\subsubsection{TiPOLOGÍAS DEL DOBLE}

Para este apartado, recojo las tipologías desarrolladas por Lubomír Doležel, Rebeca Martín y Juan Bargalló.

Partiendo del concepto de identidad personal, Doležel distingue tres temas (1985: 464-468): el tema Orlando, el tema Amphitryon y el tema del doble. En el primer caso, un individuo (X) se encarna alternativamente en múltiples mundos ficcionales (W, $\mathrm{W}^{1}, \mathrm{~W}^{2}$, etc.). En el caso del tema Amphitryon, en un mismo mundo ficcional (W), encontramos dos individuos (X e Y) con identidades personales distintas, compartiendo características tan semejantes que su identificación resulta difícil, ya que son homomórficos. Es el caso de los «gemelos idénticos» o «Doppelgängen» cuya revelación de sus respectivas identidades pone fin a la confusión generada únicamente en los habitantes de su mundo ficcional. En cuanto al tercer tema, el tema del doble, encontramos en un mismo mundo ficcional (W) dos encarnaciones alternativas (X y X') de un mismo individuo que pueden coexistir e interactuar (El doble de Dostoievski) o excluirse mutuamente sin posibilidad de coexistir ni interactuar (El extraño caso del doctor Jekyll y Mister Hyde de R.L. Stevenson). Según Doležel, este tercer tema constituye el doble en sentido estricto. En este tercer caso se requiere una manipulación más radical del rasgo semántico de la compossibilité o compatibilidad además del concepto de la identidad personal aquí expuesto. Para el autor, los mundos ficcionales son constituidos por el conjunto de individuos ficticios compossibles o componibles. Con este término, el autor se refiere a la capacidad para la coexistencia y la interacción. Para ilustrarlo con un ejemplo, Doležel nos indica como Emma Bovary es compossible con Charles Bovary, sin embargo, no lo es con Iván Karamazov. Para que estos dos últimos personajes fuesen compossibles, sería necesario construir un nuevo mundo ficcional.

El autor termina su clasificación exponiendo tres tipos de construcción del tercer tema, del tema del doble. En primer lugar, podemos encontrar la fusión de dos individuos $\mathrm{X}$ y 
X’) originalmente separados que se produce de manera gradual («William Wilson») o bruscamente como en una aparición (El doble o El retrato de Dorian Gray). En segundo lugar, la fisión o división de un individuo originalmente simple bien porque un órgano («La nariz» de Nikolaï Gogol) o bien porque una parte («La sombra» de Hans Christian Andersen) se disgrega de él. En tercer lugar, un proceso de metamorfosis reversible (El extraño caso del doctor Jekyll y Mister Hyde de R.L. Stevenson) o irreversible (Orlando de Virginia Woolf y La metamorfosis de Kafka).

La tipología presentada por Martín López (2006: 18-19) parte de la definición que Jean Paul hace de Doppelgänger, sin embargo, dicha definición podría ser aplicable tanto al tema Amphitryon, como al tema del doble, ya que la autora considera que el doble aparece cuando dos incorporaciones del mismo personaje coexisten en un mismo mundo ficcional, cuando el individuo se contempla a sí mismo. Martín enumera tres variantes que en principio se asemejan a la tipología de Doležel; sin embargo, existen diferencias reseñables. Su primera variante presenta al mismo individuo existiendo en dos o más mundos alternos que parece coincidir con el tema Orlando. En la segunda variante, dos individuos con identidades distintas, pero homomórficos, coexisten en el mismo mundo ficcional, lo que parece asimilarlo al tema Amphitryon. Sin embargo, añade que este desdoblamiento puede originarse por «causas materiales como el espejo, la sombra, la fotografía, el retrato, la estatua o el muñeco» propios algunos de ellos del tema del doble de Doležel en su construcción por fusión o por fisión. Además, el término desdoblamiento hace referencia bien a la fusión de dos partes de una misma entidad como a la escisión o fisión en fragmentos de una identidad única, no tanto a la realidad de dos identidades completamente autónomas que son difíciles de diferenciar por los sentidos. En la tercera variante, solo hace referencia a la asistencia a sus propias exequias del individuo en cuestión, lo que delimita excesivamente el campo.

Bargalló (1994: 15-17) sigue los postulados de la tipología de Doležel, resaltando algunas diferencias en el tercer modo de construcción del tema del doble cuando diferencia tres posibles procesos de metamorfosis: la que origina una forma humana diferente («Míster Hyde»), la que origina una forma distinta pero plasmada en una entidad no humana (el «retrato» de Dorian Gray) o, directamente, la que origina una forma y entidad no humanas (el «escarabajo» de Kafka). El primer caso coincide con Doležel, mientras que el segundo estaría tipificado en el modo de construcción por fusión no gradual del autor citado, en donde diferencia «entité fictionnelle humanine» y «non humaine» (469). Sin embargo, Bargalló puntualiza lo siguiente: 
Para que la forma resultante pueda considerarse desdoblamiento de la originaria, entendemos que debe revestir la «forma humana», aunque ésta se manifieste a través de una «entidad no humana» Por ello, englobamos bajo la denominación de desdoblamiento el que tiene lugar en El retrato de Dorian Gray y excluimos de dicho concepto el que se produce en La Metamorfosis (Bargalló, 1994: 17).

\section{Muerte EN LA DANÇA GENERAL}

\subsection{MOTIVACIÓN AUTORAL PARA LA CREACIÓN DEL PERSONAJE}

La aparición de las Danzas de la Muerte en la edad media parece coincidir en el tiempo no solo con la propagación de la peste negra por todo Europa entre 1347 y 1352 (Herrera, 2016: 45), sino con la presencia de otras enfermedades como el ergotismo — tanto en su variante gangrenosa como convulsiva- y con las penurias a nivel económico que acompañaron a la crisis del siglo XIV (Deyermond, 1968: 268). En el caso de la peste (Valdeón, 1998: 282-283), las muertes súbitas que provocó no solo son el punto de partida de «una gran explosión de agresividad, como se puso de manifiesto [...] en los «pogroms» de la corona de Aragón o de diversas ciudades de la cuenca del Rhin», sino también de autoagresividad plasmada en la proliferación de flagelantes que recorrieron Europa «azotándose como forma de espiar los pecados cometidos para intentar aplacar la ira divina». Según Julio Valdeón (1998: 283), el impacto que produjeron las epidemias causó una «angustia existencial» recogida en las artes y las letras a partir de la segunda mitad del siglo XIV. La muerte se va convirtiendo progresivamente en «una angustiosa obsesión, en un oscuro y no deseado final con el que concluye el disfrute de la sensualidad de la vida». La necesidad de plasmar en el arte esta angustiosa obsesión o cualquier experiencia traumática de una sociedad es un impulso del ser humano:

Image-making is one of those urges that define humans. The fact that some religions try to curb it only shows that it is basic to our orientation in the world. This urge to make an image is activated most dramatically whenever we experience situations that baffle or overwhelm us because familiar patterns of thought cannot cope with them, cannot give them shape and order that make them familiar. Death is such an experience - our own death and that of others (8). In this manner, death, too, rather than remaining shapeless and chaotically threatening, is made concrete and visible by our creative imagination (Guthke, 1999: 10). 
Romano y Tenenti (1980: 104-109) consideran que esta propagación parece deberse más bien a una mayor meditación personal sobre el destino del hombre, «una sensación de temor y de espanto, un soplo de horror» relacionado con el terrible espectáculo vivido, pero no directamente determinado por éste. No olvidemos que:

Según la autora [Ana Luisa Haindl], la epidemia habría acabado con el 30\% de los habitantes de Europa durante los años de su expansión, siendo las ciudades más afectadas aquellas con comercio y puertos como Marsella y Albi, donde murió más del 60\% de sus habitantes (Haindl, 2010: 3).

Quizás las experiencias vividas pudieran mover a los diferentes autores de aquella época a preguntarse quiénes eran y si realmente eran quienes creían ser debido a este punto de inflexión propiciado por las calamidades sobrevenidas.

Teniendo esto en consideración y recordado las palabras de Rank, Kraus, Robert Rogers y Miyoshi que atribuían a los autores que utilizaban el motivo literario del doble un malestar psicológico que descargarían sobre un bouc émissaire, sobre un chivo expiatorio; podemos aventurar a los autores de las Danzas también un malestar psicológico cuya encarnación expiatoria sería Muerte ${ }^{4}$, el personaje principal de la DG. Este malestar psicológico estaría provocado no solo por el número de muertes súbitas que las epidemias originaron, sino por la dificultad en aceptar, asimilar y gestionar psicológicamente tal volumen de fallecimientos que propiciaron tanto la agresividad como la autoagresividad ya mencionadas. Según Velázquez Ezquerra, el doble sería:

[...] la proyección plástica de una serie de pulsiones conflictivas no conscientes en el Autor. La noción de proyección implica las de espacialización y distanciamiento. La de plástica, el recurso a un código de imágenes y a estructuras de lo imaginario. Las pulsiones van referidas a la extracción de materiales procedentes del subconsciente y a la determinación del Tema en una alternancia metonímica-metafórica (Velázquez, 1982: 48).

El personaje del Muerte materializaría el lado oscuro que el individuo o el personaje pretende desterrar de su vida cotidiana, exteriorizaría los aspectos negativos reprimidos a través de una personificación que atormenta con su presencia al protagonista o encarnaría la parte de la psique a integrar materializada en una figura externa: Muerte. Sí cada uno de los estados representados encarna el ideal —es decir, la máscara para situarnos en el mundo, la fachada que se intenta proyectar-, Muerte encarnaría lo real, lo inevitable, la finitud de

\footnotetext{
${ }^{4}$ De ahora en adelante llamaré por su «nombre propio» (Zubillaga, 2004: 55-56) a la personificación de la muerte, sin emplear el artículo, para diferenciar al personaje protagonista de la Dança de la etapa final o colofón de la vida humana.
} 
dichos estados. Se desvela así el engaño, la realidad que subyace a la apariencia de los estados representados: su finitud y fragilidad; obligando a observar descarnadamente dicha realidad.

El encuentro en sí supone una amenaza objetiva que hay que intentar posponer. Cada personaje se enfrenta al fatídico final en el que Muerte puede ridiculizarlo deliberadamente ante el resto — tildando de clerizón al diácono, de don Sacristanejo al sacristán, de don Taleguero al santero, de vicioso al abad - o llamarlo irónicamente «amigo» (41A, 45A, $63 \mathrm{~A}$ y $75 \mathrm{~A})$. El encuentro con Muerte, en la mayoría de los casos representados, causa incomodidad, ansiedad, angustia y desasosiego, ya que se produce tanto una duplicación «psychologique» por las diversas imágenes especulares que se nos muestran como una duplicación «fantastique» por la presencia de una momia o esqueleto que habla y con quien es posible conversar lo que supone una anomalía perturbadora en el orden natural de las cosas.

\subsection{LA DANZA DE LA MUERTE Y SUS DIFERENTES MANIFESTACIONES}

La imagen que tenemos de la muerte se configura a partir de la relación y la actitud que mantenemos con la finitud de nuestra vida. Dicha imagen queda plasmada en los textos y las artes figurativas de las diferentes épocas, mostrando a lo largo de la historia una evolución que nos habla en gran medida de los cambios en las vivencias y las creencias. Así lo indica Karl Siegfried Guthke cuando dice que:

To speak about life and its possible significance is to speak about death: about our image of death, since we define and understand and shape our life with a view to its ultimate «other» $[. .$.$] , what we «think» about death emerges in the$ image we form odd death as the radical opposite of our being and hence the focal point of our search for ourselves (Guthke, 1999: 10).

La presencia de la $D M$ en la cultura religiosa, en la literatura y en la iconográfica europeas es un hecho sorprendentemente reciente, ya que no encontramos indicios en toda la tradición cristiana hasta finales del siglo XIII, desarrollándose en el siglo XIV y sobre todo en el XV (Holbein, 2008: 7), concretamente, a partir de los años inmediatamente posteriores a la gran peste europea (Infantes, 1997: 109). A partir de la segunda mitad del siglo XIII, «la muerte comienza a ser protagonista de una manera obsesiva en la literatura, en la iconografía y en los sermones de los predicadores, lo que conlleva una actitud cada vez más común de miedo hacia la muerte» (Mira Miralles, 2008-2009: 301; Herrera, 2016: 47).

Víctor Infantes (1997: 21-22) describe la anónima DM como: 
[...] una sucesión de textos e imágenes presididas por la Muerte como personaje central — generalmente representada por un esqueleto, un cadáver o un vivo en descomposición - y que, en actitud de danzar, dialoga y arrastra uno por uno a una relación de personajes habitualmente representativos de las diferentes clases sociales. Definida así, estaríamos ante una Danza de la Muerte que podríamos denominar completa, es decir, con texto literario y representación gráfica, nunca superpuestas o integradas, sino manteniendo su condición de universos estéticos particulares. [...] pero lo más habitual es la carencia de uno de los elementos y más todavía la fragmentación —ocasional o premeditada— de ambos.

Dentro de las diferentes expresiones artísticas encontramos los frescos de la iglesia de la Trinidad en Hrastovlje (Eslovenia), de Santa María en Lübeck (Alemania), de Kermaria en la Bretaña francesa, del oratorio de disciplinas en Clusone (Bergamo, Italia) o del Cementerio de los Inocentes en Paris entre otros:

The first Dance of Death mural was executed shortly after, at the Paris Cemetery of the Holy Innocents in 1424-5, [...] The Paris mural was captured and adapted in print in 1485 by Guyot Marchant and turned into a popular pamphlet, which underwent many editions. Through contacts in Lyon, with which the Basle printing industry had strong links, Holbein might have seen recent editions printed in 1519 or 1523 (Zemon, 1959: 97).

Así mismo, existes gran cantidad de ilustraciones xilográficas en diferentes textos (Sánchez, 1999: 164) como la portada de los Sermones de Johannes Geiler (Estrasburgo: G. Grüniger, 1515) o los grabados de Holbein que adornan un sermón de S. Cipriano y otro de S. Juan Crisóstomo (Lyón: G. Frellone, 1549) además de: «His iconic woodcut series Pictures of Death, commonly called The Dance of Death, [...]. The series originally numbered fifty-one blocks, of which forty-one were printed» (Holbein, 2016: 93).

En cuanto a los escritos, contamos con un texto hispánico fechado en 1600 y titulado: la Primera parte de las cien oraciones fúnebres en que se considera la vida y sus miserias, la muerte y sus provechos de fray Luis de Rebolledo que fue compuesto como manual de predicadores. En él, el autor hace «un riguroso recorrido de la escala social» «al modo implacable» de la DM (Infantes, 1997: 327) unos dos siglos después de la aparición de Dança General de la muerte $(D G)$. El texto de nuestra $D G$ —eslabón hispánico en la cadena europea de la DM (Morreale, 1991: 10) — carece de imágenes a diferencia de la Danse macabre y la Wurzburger Totentanz. Según Infantes (1997: 152), existen dudas razonables sobre el origen de este género y sobre cuál es el texto primigenio completo de la $D M$, ya que lo disputan la versión francesa (Danse macabre), la alemana (Wurzburger Totentans) y la española (DG). Para comprender mejor la actitud y apariencia de los personajes de la $D M$, es importante fijarnos en sus representaciones gráficas y así — con esa mirada - leer el texto de la $D G$. 
Como indica en la introducción realizada por David A. Fein de The Danse Macabre printed by Guyot Marchant, 1485 (2013: 3), las xilografías recogidos en el folleto de Guyot no muestran una danza de «la muerte» sino una danza de «los muertos». Cada uno de los estamentos representados está emparejado con una contraparte muerta más semejante a una momia que a un esqueleto. Esta oposición entre los vivos y los muertos opera en diferentes niveles. En un primer nivel, tenemos la vestimenta que identifica la posición específica en la jerarquía social de los vivos, tanto en la manera de vestir como en los objetos simbólicos que portan. Por el contrario, las figuras de sus muertos aparecen desprovistas de vestimenta y mostrando su carne e incluso sus huesos, recordando a sus respectivas parejas vivientes la superficialidad y el sinsentido de las distinciones materiales y sociales que separan a una clase de otra. En un segundo nivel, tenemos la actitud que les contrapone a través de sus posturas corporales. Mientras que los vivos permanecen relativamente inmóviles o en actitud de resistencia, sus cadáveres intercalados en serie continua, en sfilata (Holbein, 2008: 11), muestran la fluidez y la naturalidad de movimientos propias de una danza. Sin embargo, Guthke contradice a Fein al exponer que:

$[\ldots]$ the typical Dance of Death, frequently both pictorial and literary, presents not a dance of the dead, but a dance of Death with the living, with the sinners to whom he addresses (Guthke, 1999: 56-57).

La iconografía de la imagen de la muerte fluctuará entre el cuerpo con signos de descomposición y jirones de ropa (Holbein, 2008: 10) —una momia desnuda, podrida, asexuada y muy animada (Ariès, 2000: 133) — y el esqueleto. Según Guthke (1999: 43-44), la iconografía de la muerte como esqueleto no se desarrolló hasta el siglo XIII, y su consolidación como personificación de la muerte, en el XIV (van Marle, 1932: 363). Este esqueleto podrías ser hombre o mujer, y serán los atributos que porte los que marquen la diferencia — «such as the scissors alluding to Atropos, a trumpet, a drum, a gravedigger's shovel [...] an arquebus, [...] a beard [or] a pendulous bosom». Sin embargo (Guthke, 1999: 63), en los que respecta a la $D G$, aunque Muerte es concebida como masculina desde el principio, se transforma en femenina para amoldarse al patrón heterosexual convencional, ajustando su papel al género contrario de la pareja de baile. Ajuste que también podemos observar en su homóloga italiana del siglo XV titulada El Ballo della morte.

Las representaciones de los frescos y grabados que en un primer momento muestran a Muerte como una momia asexuada con signos de descomposición, parecen evolucionar hacia una unificación de los cadáveres en un prototipo común también asexuado: 
el esqueleto. Las representaciones de la danza de los muertos remarcan un vínculo entre estos y los vivos, mientras que la consolidación del esqueleto como personificación única en la danza de la muerte rompe ese vínculo de pares marcando una mayor distancia. Esta segunda imagen menos afín a las respectivas parejas de baile la hace más concreta y aprehensible, por tanto, menos carente de forma y caóticamente amenazante. Sea como fuere, el objetivo es hacer soportable una realidad que desbordaba los límites de la aceptación humana.

\subsection{MUERTE EN LA DG}

La versión española de la $D G$ aparece recogida en un manuscrito misceláneo de la biblioteca de El Escorial (Ms. b.IV.21) entre las siguientes obras:

Los Proverbios Morales de Sem Tob (fols. I - 86v $\mathrm{v}^{\circ}$ ), la Doctrina de la discriçión de Pedro de Veragüe (fols. $88 \mathrm{r}^{\circ}-108 \mathrm{r}^{\circ}$ ), nuestra Dança (fols. $109 \mathrm{r}^{\circ}-129 \mathrm{r}^{\circ}$ ), la Revelación de un ermitaño (fols. $129 \mathrm{v}^{\circ}-135 \mathrm{v}^{\circ}$ ) y el Poema de Fernán González (fols. $136 \mathrm{r}^{\circ}-190 \mathrm{v}^{\circ}$ ) (Infantes, 1997: 228-229).

Según Infantes (1997: 230), si atendemos a las fechas de redacción de las obras que se incluyen en el códice, desde el c. 1250 del Poema de Fernán González hasta el c. 1430 de la Doctrina, la redacción original de la $D G$ se situaría entre 1360 y $1390^{5}$.

El texto manuscrito consta de 79 estrofas en octavas castellanas o de arte mayor ${ }^{6} \mathrm{y}$ comienza con un proemio en prosa tras el cual habla Muerte (estrofas I, II, III y IV) en diálogo con un predicador (V, VI y VII). Tras el mismo, retoma la palabra (VIII) dirigiéndose a dos doncellas a las que considera ahora sus esposas (IX, y X $)^{7}$ dando así comienzo a una sucesión de diálogos jerárquicamente decrecientes entre Muerte y los representantes de los diferentes estados del mundo (proemio de la $D G$ ), alternando, casi de manera perfecta, los estados clericales con los civiles a diferencia de la edición sevillana.

La individualización del morir queda representada a través de los sucesivos diálogos que copila la $D G$. Estos diálogos son posibles gracias a la conversión en personaje principal de la propia muerte por medio de su personificación, otorgándole nombre propio: Muerte (Zubillaga, 2004: 55-56). Cada uno de los personajes entabla un encuentro de tú a tú con la

\footnotetext{
${ }^{5}$ Según Julio Valdeón Baruque (1980): «La peste negra afectó a España entre los años 1348 y 1350», en Historia 16, no 56: 60-66.

6 Según Josep M. Solà-Solé, «se trata es un tipo de estrofa favorito de la poesía didáctica y religiosa del siglo XV» (1981: 15).

${ }^{7}$ La muerte aparece como esposo de estas doncellas en la estrofa 9h, mientras que en la estrofa 33c aparece como esposa del abad, lo que refleja su carácter ambiguo o asexuado, válido para hombres y mujeres reforzando la separación que marca su personificación entre el ser vivo y el protagonista de la Dança.
} 
figura protagonista, no de manera colectiva sino individual. Cada una de las parejas de baile coexiste e interactúa en el mismo mundo ficcional. Cada pareja de baile comparte el mismo conjunto de individuos compossibles. Sin embargo, este diálogo personal es fruto del desdoblamiento de la propia identidad del ser humano en dos encarnaciones alternativas $(\mathrm{X}$ y X'), ya que una parte esencial del mismo, su muerte, abandona su morada para encararse con la parte que ha abandonado, de modo que «el individuo se contempla a sí mismo como un objeto ajeno gracias a una suerte de autoscopia» (Martín López, 2006: 30). Como indica González Zymla (2014: 27):

La danza de la Muerte se construye a base de sucesivas imágenes especulares 8 del vivo en diálogo con el muerto, en realidad, dialoga consigo mismo desdoblado en el efímero esplendor de la vida y en la indigencia de la tumba9. Para emplear una expresión jurídica que se aplica literalmente a las danzas macabras, el muerto incauta al vivo ${ }^{10}$.

El autor anónimo de la $D G$ se habría proyectado a sí mismo en dos personajes, creando una dramatización de su identidad a través de estas dos entidades. Uno de los personajes representaría la parte de su ser que no quiere asumir como propia y que desearía desterrar (su sombra), y el otro personaje, su modo de estar en el mundo a través de todos los estados del mismo (¿su máscara?). Al colocarse frente a todos y cada uno de los personajes citados en la $D G$, Muerte pasa a ser «la figura central de la Dança», el personaje principal, haciendo de sus interlocutores no solo personajes secundarios, sino «títeres grotescos y espantados» (Solà-Solé, 1981: 16) que nunca saldrán victorioso de dicho duelo. Muerte atormenta a cada una de sus parejas de baile, haciendo que su valía social no tenga —valga la redundancia - valor alguno ante dicho trance. Este escarnio público, esta indefensión, hace de cada uno un títere y en algunos casos un «monigote detestable».

La creación devora a su creador quien, previamente, le había insuflado el hálito de vida por medio de la personificación como el sabio a su sombra. Siguiendo la definición que Velázquez Ezquerra hace del «Doble» (1982: 48), podríamos considerar a la DG como «la

\footnotetext{
${ }^{8}$ Las imágenes especulares de El retrato de Dorian Gray de Oscar Wilde, la película El estudiante de Praga (1913) de Hanns Heinz Ewers y el cuento «La historia del reflejo perdido» de Hoffmann remiten intertextualmente a las imágenes especulares de la Dança.

9 (Martínez Gil, 1996: 73; Claramunt, 1988: 95).

10 «La preuve que c'est le double du défunt qu'on a voulu représenter, c'est que dans la Danse macabre des femmes, la Camarde change de sexe: le squelette qui entraine la reine ou la nonne a de longs cheveux de femme accrochés à son crâne. Toutefois il faut noter, à l'encontre de cette théorie, que le mort qui agrippe le petit enfant n'est plus un enfant, mais un adulte» (Réau, 1957: 648).
} 
proyección plástica de una serie de pulsiones conflictivas no conscientes en el Autor» y que éste rechaza, plasmando en esta creación literaria lo que no puede asumir.

\section{CONCLUSIONES}

De los tres temas generados por el concepto de identidad personal (tema Orlando, tema Anfitrión y tema del doble), en la Danza se representaría el tercero, ya que —en un mismo mundo ficcional (W) - encontramos dos encarnaciones alternativas (X y X') de cada uno de los estamentos enumerados compartiendo el mismo conjunto de individuos compossibles. No se trata de dos individuos ( $\mathrm{X}$ e $\mathrm{Y}$ ) que poseen identidades personales diferentes, pero esencialmente homomórficos; sino dos encarnaciones diferentes y no homomórficas de una misma identidad personal, ya que Muerte intrínsecamente forma parte de la realidad que constituye a cada uno de los estamentos representados. Así mismo, tampoco nos encontramos ante dos identidades que llevan a confusión al resto de habitantes del mundo ficcional, confusión que termina aclarándose al final de la narración como sucede en el tema Anfitrión; sino que, como caracteriza al tema del doble, «nos vemos obligados a aceptar un mundo de ficción en el que el mismo individuo puede existir en dos encarnaciones diferentes», cada una de las parejas representadas en la Danæa.

Con respecto a las variantes paradigmáticas, hay más contrate absoluto que similitud perfecta entre cada personaje y Muerte. Recordemos que en el caso del tema del doble, a diferencia del tema Anfitrión, no es necesaria una similitud entre el protagonista y su doble. En el caso que nos atañe, cada constituyente de las diferentes parejas de baile presenta más diferencias que similitudes, aunque haya atributos en las representaciones pictóricas de Muerte que los vinculen con su partenaire.

Así mismo, en cuanto a las variantes sintagmáticas, en todos los casos que encontramos en el texto, los miembros de cada una de las parejas de baile coexisten e interactúan en el mismo espacio y tiempo — como en El doble de Dostoievski- sin haber una exclusión mutua — como en la obra de Stevenson-.

De los tres modos de construcción del personaje del doble explicados por Lubomír Doležel, cada pareja de baile está constituida por dos individuos originalmente separados que, a través de la fusión devendrán en una única encarnación tras la muerte del «estamento» representado y el triunfo de Muerte. En el caso de este doble por fusión, la aparición del 
doble en este mundo ficcional, en vez de gradual o progresiva, es brusca, repentina y — sobre todo- inmediata como en el caso de El doble de Dostoievski o de El retrato de Dorian Gray de Oscar Wilde. La cuestión sería delimitar si el personaje de Muerte se identifica más con une entité bumaine como en Dostoievski o con une entité fictionnelle non bumaine como el retrato en Wilde. La representación de una momia en descomposición o un esqueleto con el que dialogar durante el baile parece encajar mejor con la entité bumaine en detrimento de la entité fictionnelle representada por el retrato de Dorian Gray.

Sin embargo, si consideramos que a partir de una única encarnación — de cada estamento representado- una parte se disgrega del protagonista encarnándose en el personaje de Muerte estaríamos ante un caso de doble por fisión. No sería la disgregación de un órgano metamorfoseado en humano como la nariz de Gogol, sino más bien la disgregación de una parte como en el caso de la sombra de Andersen.

Ante estas dos posibilidades (fusión o fisión), aunque Muerte formaba parte de cada uno de los protagonistas enumerados, el proceso de fisión de los mismos en dos encarnaciones alternativas no aparece reflejado en la $D G$. Sí la aparición repentina de Muerte que de manera «incuestionable» saca a bailar a los danzantes en contra de la voluntad y a pesar de la no aceptación de la mayoría de los mismos. Por esa razón me inclino a pensar que estamos ante la construcción de un doble por fusión de dos individuos originalmente separados y representados en todas y cada una de las diferentes parejas de baile de la $D G$. 


\section{BIBLIOGRAFÍA}

Andersen, Hans Christian; Enrique Bernárdez; Vilhelm Pedersen; Lorenz Frølich (2005): Cuentos Completos, $1^{\mathrm{a}}$ ed. Biblioteca Avrea, Madrid, Cátedra.

Ariès, Philippe (2000): Historia de la muerte en Occidente: desde la Edad Media hasta nuestros días, traducción al español de Francisco Carbajo y Richard Perrin, Barcelona, El Acantilado.

Bargalló Carraté, Juan (1994): Identidad y alteridad: aproximación al tema del doble, Sevilla, ediciones Alfar.

Claramunt Rodríguez, Salvador (1988): «La danza macabra como exponente de la iconografía de la muerte en la Baja Edad Media», en Núñez Rodríguez, Manuel y Ermelindo Portela Silva (coords.) (1988): La idea y el sentimiento de la muerte en la bistoria y en el arte de la Edad Media: Ciclo de conferencias celebrado del 1 al 5 de diciembre de 1986, I, Santiago de Compostela, Universidade de Santiago de Compostela: 93-98.

Deyermond, Alan David (1968): «El ambiente social e intelectual de la danza de la muerte», AIH, III, 267-276:

http://cvc.cervantes.es/literatura/aih/pdf/03/aih_03_1_031.pdf (último acceso: 19/06/2020).

Dieguez, Sebastian (2013): «Doubles Everywhere: Literary Contributions to the Study of the Bodily Self», en Bogousslavsky, J.; S. Dieguez (eds.) (2013): Literary Medicine: Brain Disease and Doctors in Novels, Theater, and Film. Frontiers of Neurology and Neuroscience, 31, Basel, Karger: 77-115.

Doležel, Lubomír (1985): «Le triangle du doublé: Un champ thématique», Poétique, 64, novembre: 463-472.

Dostoyevski, Fiódor (2011): El doble: Poema de Petersburgo, traducción al español de Juan López-Morillas, Madrid, Alianza editorial.

Fein, David A. (trad.) (2013): The Danse Macabre (Printed by Guyot Marchant, 1485), Medieval and Renaissance Texts and Studies 446, Tempe (Arizona), ACMRS (Arizona Center for Medieval and Renaissance Studies).

Genette, Gérard (1998): Nuevo Discurso del Relato, traducción al español de Marisa Rodríguez Tapia, Madrid, Cátedra. [texto original 1983].

González Zymla, Herbert (2014): «La Danza Macabra», Revista Digital de Iconografía Medieval, VI, 11: 23-51. 
Gubern, Román (2002): Máscaras de la ficción, Barcelona, Anagrama.

Guthke, Karl Siegfried (1999): The gender of death: a cultural history in art and literature, Cambridge, Cambridge University Press.

Haindl, Ana Luisa (2010): «La peste negra», Arqueología, historia y viajes sobre el mundo medieval 35: 56-69.

Herdman, John (1990): The Double in Nineteenth-Century Fiction, London, MacMillan Press.

Herrera Cabello, Judith (2016): «La imaginería de la Muerte en la Baja Edad Media», Anejos de Estudios Clásicos Medievales y Renacentistas, 12: 38-61, Santiago.

Herrero Cecilia, Juan (2011): «Figuras y significaciones del mito del doble en la literatura: teorías explicativas», Cédille: Revista de Estudios Franceses. Monografías, 2: 15-48.

Holbein, Hans (2008): La danza de la muerte. Seguido de un texto de John Ruskin y del códice del Escorial, traducción al español de Juan Barja y Juan Calatrava, Madrid, Abada.

Holbein, Hans (2016): The Dance of Death. Commentary by Ulinka Rublack, Great Britain, Penguin Classics.

Infantes, Víctor (1997): Las danzas de la muerte: génesis y desarrollo de un género medieval (siglos XIIIXVII), Salamanca, Ediciones Universidad de Salamanca.

Jourde, Pierre et Tortonese, Paolo (2005): Visages du doublé: un thème littéraire, Paris, Armand Colin.

Jung, Carl G. $\left(1970^{2}\right)$ : AION: Researches into the Phenomenology of the Self, The Collected Works of the C.g. Jung, 9-2, London, Routledge.

Martín López, Rebeca (2006): Las manifestaciones del doble en la narrativa breve española contemporánea:

https://www.tdx.cat/bitstream/handle/10803/4876/rml1de1.pdf?sequence=1\&i

sAllowed=y (último acceso: 19/06/2020).

Martínez Gil, Fernando (1996): La Muerte Vivida. Muerte y Sociedad en Castilla durante la Baja Edad Media, Toledo, Diputación Provincial de Toledo.

Mira Miralles, Isabel (2008-2009): “"Muerte que a todos convidas”: La muerte en la literatura hispánica medieval», Revista de lenguas y literaturas catalana, gallega y vasca 14: 291-326: http://e-spacio.uned.es/fez/eserv.php?pid=bibliuned:Llcgv-2008-2009-143180\&dsID=Documento.pdf (último acceso: 19/06/2020).

Morreale, Margherita (1991): «Dança General de la Muerte», Revista de Literatura Medieval 3: $9-52$.

Rank, Otto (2001): Don Juan et le Double, Paris, Éditions Payot \& Rivages. 
Réau, Louis (1957): Iconographie de l'art chrétien. Tome second: Iconographie de la Bible - Nouveau Testament, Paris, Presses universitaires de France.

Romano, Ruggiero y Alberto Tenenti (1980): Historia Universal Siglo XXI. Los fundamentos del mundo moderno. Edad Media tardía, Renacimiento, Reforma, XII, traducción al español de Marcial Suárez, Madrid, Siglo XXI.

Sánchez, Manuel Ambrosio (ed. y est.) (1999): Un Sermonario Castellano Medieval vol. I, Salamanca, Ediciones Universidad de Salamanca.

Solà-Solé, Josep M. (1981): La Dança general de la muerte, Barcelona, Puvill-editor.

Valdeón Baruque, Julio (1998): «El ritmo del individuo: en las puertas de la pobreza, de la enfermedad, de la vejez, de la muerte», en De la Iglesia Duarte, José Ignacio (coord.): La vida cotidiana en la Edad Media: VIII Semana de Estudios Medievales: Nájera, del 4 al 8 de agosto de 1997, Nájera, Instituto de Estudios Riojanos: 275-288.

Valdeón Baruque, Julio (1980): «La muerte negra en la península», Historia 16, 56, 60-66: http://www.vallenajerilla.com/berceo/valdeon/muertenegraenlapeninsula.htm (último acceso: 19/06/2020).

Van Marle, Raimond (1932): Iconographie de l'art profane au Moyen-Age et à la Renaissance, II, The Hague, Nijhoff.

Velázquez Ezquerra, J. Ignacio (1982): «Aspectos textual y psicoanalítico del tema del doble en la literatura. (I). Los desdoblamientos de M. Tournier», Cuadernos de investigación filologica 8: 39-53, Logroño, Universidad de La Rioja.

Webber, Andrew J. (1996): The Doppelgänger: Double Visions in German Literature, Oxford, Clarendon Press.

Zemon Davis, Natalie (1959): «Holbein's Pictures of Death and the Reformation at Lyons», Studies in the Renaissance, 3: 97-130.

Zubillaga, Carina (2004): «La configuración de la muerte en el Libro de buen amor como huella textual de un mundo en crisis», Revista de poética medieval, 13: 51-72, Alcalá de Henares, Universidad de Alcalá de Henares.

Zweig, Connie and Jeremiah Abrams, eds. (2004): Encuentro con la sombra: El poder del lado oculto de la naturaleza bumana, Biblioteca de la nueva conciencia, Barcelona, Kairós. 


\section{Daniel Añua-Tejedor}

Daniel Añua-Tejedor es licenciado en Filología Inglesa y en Filología Hispánica por la Universidad del País Vasco/Euskal Herriko Unibertsitatea. Estudió el Máster en Literatura Comparada y Estudios Literarios por la misma Universidad. En marzo de 2015 alcanzó el título de doctor tras defender su tesis titulada: El Proceso de deshumanización del morir en la literatura hispánica medieval. Como investigador independiente ha publicado varios artículos referentes a la literatura medieval y continúa con esta labor investigadora.

https://orcid.org/0000-0002-2087-1175

Contact information:

Email: danua001@hotmail.com 